International Journal of Social Science and Economic Research

ISSN: 2455-8834

Volume:06, Issue:01 "January 2021"

\title{
ROLE OF LANGUAGE IN LEARNING
}

\author{
Anshuman Singh \\ Vasant Valley School, Vasant Kunj, New Delhi \\ DOI: 10.46609/IJSSER.2021.v06i01.018 URL: https://doi.org/10.46609/IJSSER.2021.v06i01.018
}

\begin{abstract}
This paper tries to study the New Education Policy which primarily addresses the issue of language in India. Since 1947, the literacy rate of the country has increased from a mere $12 \%$ to a mammoth $77.7 \%$ in 2020. However, industrialists argue that the employability of Indian matriculates remains a huge concern and is not in sync with the increasing demand of the tourism and hospitality industry. Accommodating India's large linguistic diversity is a complex issue and involves accommodating a large number of issues such as pride in regional languages while at the same time dealing with the issue of universality. This paper argues that the New Education Policy 2020 will reduce the employability of Indian Graduates from low-income households and further investigates the role of the English language in developing countries.
\end{abstract}

Keywords: Learning, Language ,linguistic, Education, Tourism.

\section{INTRODUCTION}

Education and development of a nation are generally relative to each other. Education's contribution to economic growth, distribution of wealth, poverty reduction, reduction in inequalities, and socio-political transformation of the societies is immense.

Although India aims at transforming itself into a knowledge society to catch up with developed nations in areas of economic growth, technological progress, it is yet to attain the desired level. Education in India as it developed over the years, presents a mixed picture. Despite very impressive growth in all levels of education during the last seven decades after independence, India's quest for universal elementary education is still not fulfilled; secondary education has not progressed enough; vocational and technical secondary education is yet to take off, despite several initiatives taken in the field of higher education they have not created adequate skills and knowledge for decent jobs in the labor market. It faces umpteen challenges in the rapidly changing socio-economic and political global and national environments, calling for sound public policy. 


\section{International Journal of Social Science and Economic Research}

ISSN: $2455-8834$

Volume:06, Issue:01 "January 2021"

Thus, the first National Policy of Education was formulated in 1968. One of its features was to pay more attention to the learning of regional languages, outlining the "three-language formula", viz. Hindi, English, and Regional Language - to be applied in secondary education. However, this was met with stiff resistance by some Non-Hindi States (esp. Tamil Nadu). In fact, Tamil Nadu had been vehemently and violently opposing the imposition of Hindi since even before the Independence of India. Therefore, the three language did not take off the way it was envisaged.

This was followed by the National Policy of Education, 1986 (modified in 1992).

The current National Education Policy 2020 proposes that "... wherever possible, the medium of instruction until at least Grade 5, but preferably till Grade 8 and beyond, will be the home language/mother-tongue/local language/regional language. Thereafter, the home/local language shall continue to be taught as a language wherever possible. This will be followed by both public and private schools.

"As research from the National Institutes of Health in the USA clearly shows that children pick up languages extremely quickly between the ages of 2 and 8 and that multilingualism has great cognitive benefits to young students, children will be exposed to different languages early on (but with a particular emphasis on the mother tongue), starting from the Foundational Stage onwards. All languages will be taught in an enjoyable and interactive style, with plenty of interactive conversation, and with early reading and subsequently writing in the mother tongue in the early years, and with skills developed for reading and writing in other languages in Grade 3 and beyond. There will be a major effort from both the Central and State governments to invest in large numbers of language teachers in all regional languages around the country, and, in particular, for all languages mentioned in the Eighth Schedule of the Constitution of India. States, especially States from different regions of India, may enter into bilateral agreements to hire teachers in large numbers from each other, to satisfy the three-language formula in their respective States, and also to encourage the study of Indian languages across the country. Extensive use of technology will be made for teaching and learning of different languages and to popularize language learning."

There is no doubt that the New Education Policy 2020 is laudatory and based upon an idealistic view that usage of home language/mother-tongue/local language/regional language as a medium of instructions until at least Grade 5, but preferably till Grade 8 and beyond, would pave the way for a level playing field between the marginalized section of society (those who do not have access to or are not exposed to the English language) and the upper middle class and above class. It also caters to the theory that it would give a much-needed fillip to regional/vernacular language, which is currently languishing and not receiving its due recognition given the fact that 


\section{International Journal of Social Science and Economic Research}

ISSN: $2455-8834$

Volume:06, Issue:01 "January 2021"

they are generally not high up in the social ladder and are looked down upon by English speaking people, who generally hail from the more privileged section of society.

This will also boost the opportunity for locals/natives (e.g. Adivasis) to get the much-needed education in a language they are familiar with.

Not to mention that vernacular Press and Publishing Houses would stand to gain immensely as they are expected to get work orders aplenty. However, there are several arguments to be made on the flip side as well. To start with,it is akin to withdrawing a facility enjoyed by one section, instead of extending it for those who do not have access to it-- a convoluted manner to make a level playing field, instead of extending the same facility to those who did not have it. In other words, instead of withdrawing the English language - as a medium of instructions - till Grade 5 altogether, it could have been made compulsory. Of course, it could still have its share of shortcomings/deficiencies but then those could have been tackled differently with targeted efforts/measures.

The proposal, if implemented, would involve a herculean task of making translations of existing syllabi comprising books, notebooks, charts, maps \& other study materials into all regional languages. The process could not only be tedious and gargantuan but prove to be a costly affair, more so because the education sector has faced massive budget cuts. Also, the finer nuance, essence, or focus of the language/content may be lost in translation. The existing faculty, proficient in delivery in the English language, would either have to be reacquainted/retrained in regional language or have to be substituted altogether with local faculty.

The Policy, if implemented, would also give rise to some piquant situations which it does not address. What happens in a scenario where a student migrates from one state to another where the regional language (medium of instruction) is completely different?They would be entirely at sea unable to grasp a word in the new language.

The argument that this would pave the way for a level playing field between the marginalized section of society (those who do not have access to or are not exposed to the English language) and the upper middle class and above class may not stand ground (actually, backfire). It is because the students hailing from upper-middle-class society (who are anyway fairly proficient in English) would still have a better grip of English and will always be one up on the marginalized section of society who would not have many means to learn/acquire/brush up on English in the latter part of their career. This will make the gulf between the two sections wider.

The students of lower strata of society will anyway be in a disadvantaged position vis-à-vis the upper-class students in the white-collar job market (especially MNCs and other top corporates), where the official mode of communication is English. Our country is known as a powerhouse in 
International Journal of Social Science and Economic Research

ISSN: 2455-8834

Volume:06, Issue:01 "January 2021"

the IT sector not only because of the technical skills of our graduates but also to a large extent because of their language (English) skills. They in turn make a name for themselves and also attract scarce foreign exchange for the nation. Implementation of this policy would fritter this head start away that has been acquired by toiling over the years.

Thus, a holistic view needs to be taken over the medium (language) of instructions, instead of getting mired over this issue in a country - which is beset with many serious and pressing issues already - which is so linguistically diverse. In a nutshell, the question of language should best be left to the discretion of the individual States of the Union to avoid any untoward incidents.

\section{INCOME INEQUALITY IN INDIA AND ACCESSIBILITY TO TUITIONS}

Based on a report by the NSSO in 2017 , the top $10 \%$ of the Indian population holds $77 \%$ of the total GDP. Of the total wealth generated in $2017,73 \%$ went to the top $1 \%$ while 67 million Indians who comprise the bottom $50 \%$ witnessed only a $1 \%$ increase in wealth.

It goes without saying that the availability of wealth has a strong correlation with accessibility to tuitions, coaching classes, and language bridge classes.

A study ${ }^{6}$ reported that in the urban cities of Andhra Pradesh, Uttar Pradesh, Kerala and Maharashtra(which are primarily occupied by wealthier households) $64 \%$ of students took private coaching classes for various subjects vis a vis rural areas in which a meagre $29 \%$ received tuition classes.

A report from the financial express also revealed that the average income of a resident from Urban India earns 98,435 INR vis a vis a resident from rural India who earns 40,925 INR. In terms of the availability of jobs, urban India has greater availability of jobs for highly skilled workers and invites more FDI.

Clearly, the need of the hour for the Government is to reduce this large inequality by improving the quality of education, bringing universality in education and creating more job opportunities. Employment can only be created by incentivizing greater investments from MNCs by building a more competent English speaking population by prioritising teaching the language at an earlier stage for all income groups.

\section{MEANS OF EMPLOYMENT AND NEED FOR AN ENGLISH SPEAKING POPULATION}

\begin{tabular}{|l|c|c|}
\hline Industry Sector & \multicolumn{2}{|c|}{ Thousands of Jobs } \\
\hline & 2019 & 2029 \\
\hline
\end{tabular}


International Journal of Social Science and Economic Research

ISSN: 2455-8834

Volume:06, Issue:01 "January 2021"

\begin{tabular}{|l|r|r|}
\hline Total $\underline{(1)}$ & $162,795.6$ & $168,834.7$ \\
\hline Non Agricultural wage and salary $\underline{(2)}$ & $151,709.7$ & $158,115.6$ \\
\hline Goods-producing, excluding agriculture & $21,016.3$ & $20,964.9$ \\
\hline Mining & 684.6 & 777.8 \\
\hline Construction & $7,492.2$ & $7,792.4$ \\
\hline Manufacturing & $12,839.5$ & $12,394.7$ \\
\hline $\begin{array}{l}\text { Services-providing excluding special } \\
\text { industries }\end{array}$ & $130,693.4$ & $137,150.7$ \\
\hline Utilities & 549.0 & 506.7 \\
\hline Wholesale trade & $5,903.4$ & $5,801.3$ \\
\hline Retail trade & $15,644.2$ & $15,275.9$ \\
\hline Transportation and warehousing & $5,618.1$ & $5,944.1$ \\
\hline Information & $2,859.4$ & $2,853.2$ \\
\hline Financial activities & $8,746.0$ & $8,799.9$ \\
\hline Professional and business services & $21,313.1$ & $22,831.4$ \\
\hline Educational services & $3,764.5$ & $4,230.0$ \\
\hline Health care and social assistance & $20,412.6$ & $23,491.7$ \\
\hline Leisure and hospitality & $16,575.9$ & $17,691.5$ \\
\hline Other services & $6,713.8$ & $6,994.7$ \\
\hline Federal government & $2,834.0$ & $2,650.4$ \\
\hline State and local government & $19,759.4$ & $20,080.0$ \\
\hline
\end{tabular}

The Bureau of Labor statistics report, shown above, clearly reveals that the service sector, hospitality industry, and healthcare are set to grow by large numbers in the following years and employers will be looking for a competent, employable English-speaking population.

Also, a report published by Business Standard in October 2020 revealed that $67 \%$ of MNCs see India as a top choice for FDI. These MNCs are looking for good communication skills.

Now that we see a need for a universal language, the question arises as to when it should be taught for maximum reception and retention.

\section{RECEPTION AT AN EARLY AGE-ANALYSIS THROUGH NEUROSCIENCE}

Children learn languages the fastest between ages 0 to 5 years. This is primarily due to 2 major reasons: Neuroplasticity and Myelination. 


\section{International Journal of Social Science and Economic Research}

ISSN: $2455-8834$

Volume:06, Issue:01 "January 2021"

Myelination $^{12}$ is the process of the covering of axons in the neuron with myelin, a substance composed of lipids and amino acids, which is responsible for the insulation of the neuron and faster conduction of nerve impulses. Since the myelin assembles voltage-gated sodium channel clusters at discrete nodes along its length it increases the process of transmission of nerve impulses and drastically enhances our ability to learn faster. Children until the age of 5 are able to learn the fastest due to this process occurring rapidly and are able to comprehend complex information very quickly and should be subjected to complex tasks such as learning a new language at this age.

Similarly, High neuroplasticity ${ }^{12}$ helps children learn faster between the ages of 0 to 5.Neuroplasticity is the ability of neural networks in the brain to mold itself through growth and re-organization. This furthers tells us that Children should be taught an essential language such as English at an early age.

In addition, the part of our brain responsible for comprehending various languages called the Wernicke's Area undergoes huge changes ${ }^{11}$ until 18 months, and children are able to expand their vocabularies the fastest in this age group.

We can clearly see that English, a means for employment, should be taught at an early age and the New Education policy fails to do justice to this biological mechanism.

Instead ,teaching children English after Grade 5 will not be feasible and children will be unable to grasp the language adequately consider: This will result in widening gaps in access to highpaying job opportunities.

This will primarily disadvantage the marginalized sections of society as these groups do not have access to private tuitions and will not be able to bridge the gap with their wealthier counterparts.

\section{CASE STUDY OF CHINA'S LANGUAGE POLICY}

China serves as an example of a country that has witnessed massive improvements in industrial growth and FDI after the prioritization of the English Language. Since China has a population of 1.4 billion, a reasonable comparison can be made with India. In 2001, guidelines ${ }^{15}$ were issued by the Ministry Of Education (MOE) regarding the introduction of English as a compulsory language in the secondary school curriculum. From 2003, the English language was made compulsory from primary 3 , and the language has been further prioritized in the curriculum in 2011. The introduction of the English language has been done at earlier stages in Metropolitan cities. 
International Journal of Social Science and Economic Research

ISSN: 2455-8834

Volume:06, Issue:01 "January 2021"

General proficiency in English has improved due to the above-mentioned policy changes. Consequently, we have seen increased investments in the nation by MNCs such as Walmart, Apple, and Dell. China's GDP per capita has also increased from 1053.11 USD to 8130 USD credit to these increased investments and prioritization of the education of the English language at earlier stages.

There is a very clear advantage of teaching English at earlier stages. Now, this paper considers the example of Uttar Pradesh and how the de-prioritization of the English language became a recipe for disaster for the state.

\section{DETERIORATION OF EDUCATION IN UTTAR PRADESH}

The state of Uttar Pradesh has a population of 231.5 million and is home to numerous languages such as Awadhi, Brajh Bhasha, Bhojpuri et cetera. This populous state had an ancient culture of education with numerous notable universities such as Benares Hindu University and Aligarh Muslim University. However, post the 1990s after the coalition government composed of Mulayam Singh Yadav and Mayawati, the state witnessed a sharp downfall.

One of the primary causes of this was the forceful implementation of regional languages at all stages of education. This led to decreased investments and the crippling of industries in the state. The industrial city of Kanpur is a prime example of it. Decreased investment in the leather industry, lack of a competent workforce, and poor communication skills led to the Manchester of the East being turned into an Industrial Graveyard.

The state also has a literacy rate of $73.7 \%$ lower than the national literacy rate of $77 \%$. The state now needs the help of World Bank aid programs to help improve its literacy rate and improve the employability of graduates.

Joblessness which primarily plagues lower-class groups has also led to increased crime rates in areas such as petty theft, dacoity, and robberies.

Clearly, de-prioritizing a universal language led to a decline in education, employability of graduates, and this consequently led to increased crime rates, de-industrialization of a state which once had immense potential.

\section{CONCLUSION}

The paper clearly discusses the various criticisms and issues with the implementation of the NEP and shows that it is insufficient in answering the question of accessibility of education and reducing the inequality between different sections of society. Historical precedence clearly indicates that a universal language such as English should be taught at an earlier age as it will 
International Journal of Social Science and Economic Research

ISSN: 2455-8834

Volume:06, Issue:01 "January 2021"

help in making the Indian youth more employable and increase their access to various other profitable opportunities

\section{REFERENCES}

[1] Duncan, Ian. "New Political Equations in North India: Mayawati, Mulayam, and Government Instability in Uttar Pradesh.” Asian Survey, vol. 37, no. 10, 1997, pp. 979-996. JSTOR, www.jstor.org/stable/2645617. Accessed 13 Nov. 2020.

[2] Dutta, Arnab. "67\% MNCs See India Among Top Choices For FDI, Says CII-EY Survey". Business-Standard.Com,2020, https://www.business-standard.com/article/current-affairs/67mncs-see-india-among-top-choices-for-fdi-says-cii-ey-survey-120101301271_1.html. Accessed 10 Nov. 2020

[3] Chowdhury, Kavita. "Kanpur: Decline Of An Industrial Hub". Business-Standard.Com, 2020, https://www.business-standard.com/article/economy-policy/kanpur-decline-of-an-industrial-hub112021400057_1.html. Accessed 10 Nov. 2020

[4] Employment of Labor Statistics,Labour Bureau http://labourbureau.gov.in

[5]India's Per Capita Income,Hindu Business https://www.thehindubusinessline.com/economy/indias-per-capita-income-rises-68-per-cent-to11254-a-month-in-fy20/article30505051.ece

[6] Sukumar, Tanay. "Is The Golden Age Of Private Tuition Over In India?". Mint, 2020, https://www.livemint.com/education/news/is-the-golden-age-of-private-tuition-over-in-india11597230452852.html. Accessed 5 Nov 2020.

[7] "India - Distribution Of Gross Domestic Product (GDP) Across Economic Sectors 2019 | Statista". Statista, 2020, https://www.statista.com/statistics/271329/distribution-of-grossdomestic-product-gdp-across-economic-sectors-in-india/.

[8] "India - WID - World Inequality Database". WID - World Inequality Database, 2020, https://wid.world/country/india/. Accessed 9 Nov 2020.

[9] "Neuroplasticity | Different Types, Facts, \& Research". Encyclopedia Britannica, 2020, https://www.britannica.com/science/neuroplasticity.

[10] "What Is Neuroplasticity? A Psychologist Explains [+14 Exercises]". Positivepsychology.com, 2020, https://positivepsychology.com/neuroplasticity/. Accessed 11 Nov 2020. 
International Journal of Social Science and Economic Research

ISSN: 2455-8834

Volume:06, Issue:01 "January 2021"

[11] "The Myelin Sheath And Myelination". Kenhub, 2020,

https://www.kenhub.com/en/library/anatomy/the-myelin-sheath-and-myelination. Accessed 12

Nov 2020.

[12]"English Language Education". Springer.com, 2020, https://www.springer.com/series/11558. Accessed 7 Nov 2020.

[13] Hu, Yuanyuan. "China'S Foreign Language Policy On Primary English Education: What'S Behind It?". Language Policy, vol 6, no. 3-4, 2007, pp. 359-376. Springer Science And Business Media LLC, doi:10.1007/s10993-007-9052-9. Accessed 8 Nov 2020.

[14] "How Young Children Learn Language | Scholastic". Scholastic.Com, 2020, https://www.scholastic.com/teachers/articles/teaching-content/how-young-children-learnlanguage/\#: : :text=Language $\% 20$ is $\% 20$ learned.,allows $\% 20$ the $\% 20$ creation $\% 20$ of $\% 20$ language. \&text $=$ In $\% 20$ the $\% 20$ first $\% 20$ years\%20of, listen\%2C\%20practice\%2C\%20and\%20learn. 